\title{
Research on brand alliance strategy innovation based on the big data analysis of consumers' attitude Take Louis Vuitton and supreme as an example
}

\author{
Kai Xiong $^{1}$ \\ ${ }^{1}$ Business School of Jianghan University, Manufacturing Industry Development Research Center on Wuhan city circle, Wuhan City, \\ Hubei Province, P.R.China
}

\begin{abstract}
As a big consumer of luxury brands, China has entered a period of rapid transformation under the impact of millennials and fashion brands. With the development of economy and the popularization of education, more and more people begin to purchase rationally, and consumers' understanding of consumption is also gradually diversified. Based on the big data analysis of consumers' attitude towards brand alliance, this paper puts forward some suggestions for the development of luxury brand and fashion brand in the future.
\end{abstract}

\section{Introduction}

With the development of economy and the birth of a new generation of consumers, more and more people begin to pay attention to the competition between fashion brands and luxury brands. Bain and Fondazione altagamma recently released the report on global luxury brand market monitoring in spring 2018. The report points out: in 2018, the global personal luxury brand market sales will increase by $6 \%$ to $8 \%$ year-on-year at the constant exchange rate, reaching 276 billion euro to 281 billion euro. The Chinese market and millennial consumers are still the drivers of the luxury brand industry. The global luxury brand market is expected to reach 390 billion euro by 2025 .

At the same time, the rise of street culture and high street fashion has a huge impact on the luxury brand market. Various brands of street wear have joined the luxury brand market one after another, hoping to get a share of the market. The millennial consumers are fans of street culture. Therefore, it is particularly important for the luxury brand industry to grasp the psychology of today's young people. The rise of street wear and the decline of traditional luxury brand logo reflect that luxury brand is in great crisis nowadays.

\section{Literature review}

The history of luxury brand research abroad is earlier. Wolfgang laszler of Germany takes luxury as a life attitude as the central idea in his book "luxury brings wealth" (2003). This book gives a detailed overview of the great impact of luxury on the development of human society. In the book luxury marketing and management written by Daniel Langer and Oliver hale, the concept that luxury goods can meet people's needs is different from other books. Michel shevalli, a famous luxury brand management expert, believes that luxury does not contain derogatory elements in luxury brand management. When carrying out luxury brand management, we should remove the derogatory bias against luxury goods, define luxury clearly and provide a perspective of luxury business. Overseas research on brand of street wear is in a new stage, and there are not many works. The only one is to put forward six marketing principles for supreme, which mainly focuses on hunger marketing. The two principles of ultra-low volume and timely launch of new products on Thursday attract countless fans to establish "supreme" teaching, as well as free star upper body effect publicity.

Compared with foreign countries, China tends to study the history and marketing model of luxury brands. Yu Yan and Zhao Jiguang (2014) believed that China should customize reasonable import tax and consumption tax system to guide the consumption of domestic luxury brands.[1] Chen Jie (2014) proposed that luxury brands should pay attention to the integration of network marketing.[2] Gao Xiaoqian (2014) puts forward the viewpoint of luxury source country effect, and the image of luxury brand source country will increase consumers' willingness to buy.[3] Zhu Yuliang, Yang Yixiong (2015) proposed the importance of luxury brand culture and unique marketing strategies for luxury brands.[4] Ma Qiang (2015) proposed the business ideas of domestic luxury enterprises and the direction of government support. Domestic research on fashion brand lies in the analysis of marketing mode. [5] Zhang Jing (2011) proposed that luxury goods should gradually put down

e-mailxkyx@sina.com 
their stature in order to please the new consumer market.[6] Zhang Tian (2016) believes that the consumption influencing factors and demands behind the consumption of fashion brand symbols mainly come from the fashion people's attention to personalization and the expression and catharsis of young people's emotion.[7] Chen Chunqin (2017) proposed the concept of product strategy and cultural concept, and fashion brand should pay more attention to convey a kind of cultural belief and consumption in marketing.[8]

\section{Comparison between luxury brands and fashion brands}

After the 20th century, the influence of luxury brands has gradually surpassed the luxury brands themselves. During this period, with the development of the economy, the middle class will become the largest buyers of luxury brands. Through the understanding of brand concept and brand quality, people gradually tend to be rational in luxury brand consumption. Consumers first identify with the connotation of luxury brand, and then pass the connotation to themselves through purchasing behavior to show their identity and status.

Fashion brand,which is also called street wear, originated from American street culture, is the identity and symbol of young people's subculture identity. Different from luxury brands and standardized mass brands, as an emerging force in the global trillion dollar clothing market, fashion logo has gradually released huge commercial value in the business community in recent years. New consumer groups who like popular logos like to label themselves as "different", especially after social photo sites and corresponding apps provide a "stage" for everyone. They urgently need different labels to express themselves in these new stages. All these contributed to the rise and outbreak of the street wear.

Luxury brand and fashion brand have many common points. First of all, they are scarce and unique and high price non necessities. To some extent, fashion brand and luxury brand can represent the identity status of a class of people and the attitude of pursuing high quality of life. Therefore, how to separate luxury brands from fashion brands? This paper thinks that there are three points.

Firstly, the driving force of luxury brands is to create and pursue extraordinary quality and first-class manual manufacturing. From the beginning of selection, all luxury brand materials are made by famous European manual workshops, and the materials of each cloth leather are selected by luxury brand companies. However, the tide brand obviously does not have such strict requirements in the manufacturing process. It focuses on original design, focusing on street, leisure and other elements.

Secondly, luxury brands pay more attention to the spirit of freedom and a life attitude that shows themselves. Luxury brands pay more attention to brand culture and brand stories. Each luxury brand has the story behind it. The version design is still popular until now, and it will not be forgotten because of the passage of time.
Thirdly, the purchasing groups are different. Luxury brands can be said to be bought by a large group of men, women, old and young people. The elderly aged from 80 to 80 may go to buy a new and beautiful schoolbag. The tide brand consumer group is more young group, mainly after 80,90 s and 00 , more pursuit of street culture and hiphop spirit, self-expression, and can be said that tide brand has become the main consumer goods of young men.

\section{A survey of consumers' cognition and attitude towards brand alliance}

\subsection{Research purpose}

In order to further grasp the psychological characteristics and behavior orientation of Chinese consumers towards the combination of luxury brands and fashion brands, and to understand the changes of Chinese consumers' consumption habits, the questionnaire survey was used to investigate the consumer attitudes of luxury brands and fashion brands in China.

\subsection{Research method}

The survey adopts the indifference questionnaire survey method, the survey object is the ordinary people, the survey object covers people of different ages, different occupations, different regions and different consumption views, so as to ensure the difference of the survey objects and the authenticity of the survey data. A total of 129 questionnaires were sent out and 129 were recovered, with the recovery rate of $100 \%$. Among them, 129 were valid and the effective rate was $100 \%$.

\subsection{Data analysis}

\subsubsection{Descriptive statistics analysis}

Among the 129 valid questionnaires, 45 were male, accounting for $34.88 \%$, and 84 were female, accounting for $65.12 \%$. There were 6 respondents under the age of 18 , accounting for $4.65 \%$; 107 respondents aged 18 to 25 , accounting for $82.95 \%$; 14 respondents aged 25-35, accounting for $10.85 \%$; 2 respondents over 35 , accounting for $1.55 \%$. From the above data, we can see that the public's attention to luxury goods and Brand Co branding is concentrated in 18-35 years old. Among them. The main target group was the age group of teenagers and 1825 years old. From the distribution of occupation and education background, there are 13 entrepreneurs, accounting for $10.08 \%, 12$ in the advertising fashion industry, accounting for $9.3 \%, 16$ employees in enterprises and institutions, accounting for $12.4 \%, 10$ freelancers, accounting for $7.75 \%, 63$ students, accounting for $48.84 \%$, and 15 others, accounting for $11.63 \%$. From the above data, college students will pay more attention to luxury goods and Brand Co branding. The higher the education level, the higher the awareness of luxury goods and Brand Co branding. 
In terms of income, $51.16 \%$ of the respondents with $1000-4000$ yuan, $15.5 \%$ of the respondents with income of $4000-6000$ yuan, $6.98 \%$ of the respondents with income of $6001-8000$ yuan, $3.1 \%$ of the income of $8001-$ 10000 yuan, $7.75 \%$ of the income above 10000 yuan, and $7.75 \%$ of the non-income. From the above data analysis, the degree of income determines the consumption level, so the higher the income level, the higher the purchasing power of luxury accessories.

\subsubsection{Consumer's cognitive analysis of brand alliance}

As shown in Figure 1, among the 129 valid questionnaires, $88(68.22 \%)$ thought of logo and printing, $53(41.09 \%)$ thought of integration and redesign, $20(15.5 \%)$ thought of technology, $50(38.76 \%)$ of creativity, $20(15.5 \%)$ of commercialization, $28(21.71 \%)$ of $1+1>2$ There were 40 people with high quality and low cost performance, accounting for $31.01 \%$. 58 people thought that the circulation was small and it was difficult to buy, accounting for $44.96 \%$. According to the above data, it can be analyzed that the attention to the appearance of Brand Co branding is the primary concern of consumers. For example, this brand alliance between Louis Vuitton and supreme, the logo of Louis Vuitton and the logo of supreme doubled its price. Secondly, they pay attention to their creativity and technology. Now consumers are more rational consumers and pay more attention to the texture of their design. Of course, some consumers think that the price of Brand Co branding is high, difficult to buy and low cost performance. When two brands jointly carry out marketing, we need to pay attention to this problem.

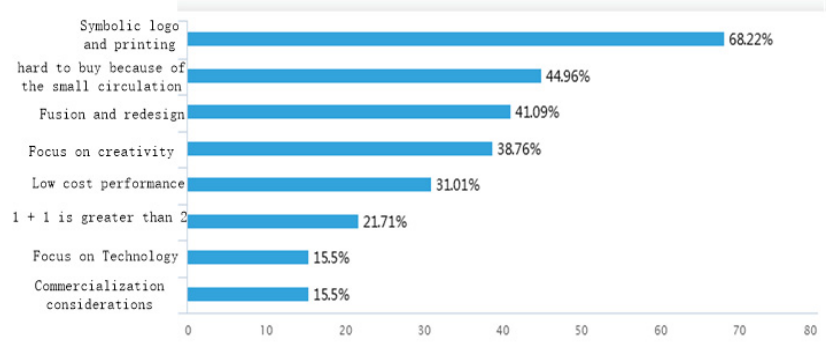

Figure 1. Consumer's cognitive of Brand Co branding

As shown in Figure 2, among the 129 valid questionnaires, $77(59.69 \%)$ have bought or heard of Louis Vuitton \& Supreme brand alliance products, and 52 (40.31\%) have not bought or heard of Louis Vuitton \& Supreme brand alliance products. According to the above data analysis, most consumers have an understanding of Louis Vuitton \& Supreme brand alliance products. Another part of consumers may not pay too much attention to the fashion brand market, which is not in line with their upper body brands, so they do not know much about the joint brand series of Louis Vuitton \& Supreme.

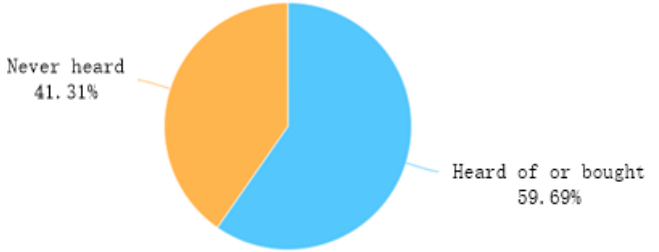

Figure 2. Ever bought or heard of $\mathrm{CO}$ branded products

\subsubsection{Analysis of consumers' attitude towards brand alliance}

As shown in figure 3, Among the 129 valid questionnaires, $67(51.94 \%)$ thought that they liked cross-border co branding and that brand co branding was strong and strong, accounting for $51.53 \%, 39.53 \%$ and $27.91 \%$ respectively. Four people $(3.1 \%)$ thought that they disliked brand alliance and that the form was greater than the content. There were 42 people with attitude, accounting for $32.56 \%$, and 9 people thought that they did not understand the brand alliance, accounting for $32.56 \%$. From the above data, we can see that the vast majority of consumers recognize brand alliance, and prefer two brands with great difference for brand alliance. This also shows that today's consumer psychology is more like chasing new things. The reason why the brand alliance of Louis Vuitton \& Supreme is successful is precisely because the brand culture of the two brands is quite different.

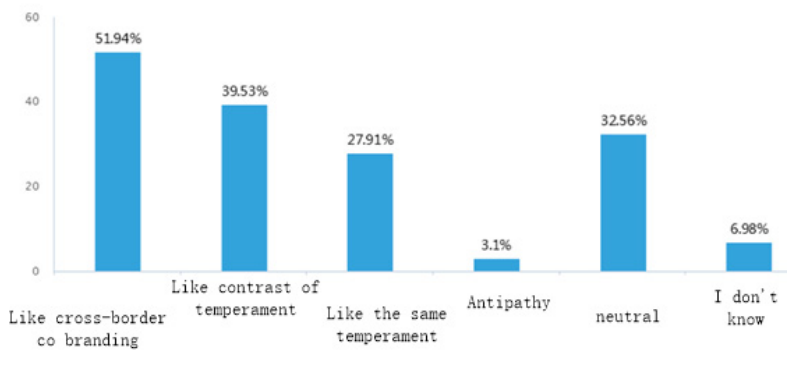

Figure 3. Consumers' attitude towards Brand Co branding

For the attitude of Louis Vuitton \& Supreme brand alliance, as shown in Table 1, among the reasons why consumers buy, the collection value accounts for $31.01 \%$; 34 people think that they are in line with their own style, accounting for $26.36 \%$; and there are 33 people who love both brands, accounting for $25.58 \%$. There are also some people because of vanity to buy, and for the star upper body and as a gift to buy reasons accounted for a very small number. On the choice of purchasing channels, $41.86 \%$ of people will choose to buy on behalf of others. Of course, $40.31 \%$ of people will choose to buy online from the official website. From this survey, we can know that consumers pay more attention to the collection value when buying brand co branding, and they can resell them in the second-hand market so as to obtain higher profits. Therefore, when the two brands are united, they should pay attention to the influence of the two brands on the young groups, and should spend efforts on publicizing the collection value of commodities. In addition, it is a double-edged sword for enterprises that young people choose to purchase on behalf of others. In this regard, we should pay attention to the spread of fake goods, which leads to the reduction of brand loyalty. 
TABLE I. MOTIVATION OF CO BRANDED BRANDS

\begin{tabular}{|l|c|c|}
\hline \multicolumn{1}{|c|}{ item } & total & \multicolumn{1}{c|}{ proportion } \\
\hline $\begin{array}{l}\text { Match your style } \\
\begin{array}{l}\text { Street star upper } \\
\text { body }\end{array}\end{array}$ & 34 & $26.36 \%$ \\
\hline Position in the trend & 25 & $15.63 \%$ \\
\hline $\begin{array}{l}\text { Design and joint } \\
\text { name }\end{array}$ & 27 & $20.93 \%$ \\
\hline Love two Brand & 33 & $25.58 \%$ \\
\hline Collection value & 40 & $31.01 \%$ \\
\hline As a gift & 21 & $16.28 \%$ \\
\hline just vanity & 30 & $23.26 \%$ \\
\hline
\end{tabular}

\subsection{Research conclusion}

Through this questionnaire survey, it is found that most people still hold a supportive attitude towards brand alliance. Due to the limited co branded items, it has brought great consumption stimulation to consumers. For modern consumers, they are more inclined to consumer goods that can bring their own sense of superiority. Therefore, if luxury brands and fashion brands choose the way of brand alliance, they should choose more brands complementary to their own brands to launch cooperative products.

\section{5 brand alliance strategy innovation of luxury brand and fashion brand}

\subsection{Brand alliance motivation}

\subsubsection{Market driven}

Street culture has become an important term in today's consumer market, fashion is leading people's taste. From the market analysis, according to the report analysis of fashion formats in 2019 published by McKinsey consulting and BOF, young people aged 20-35 have higher education level and more disposable income, so they become the target consumer groups of luxury brands and fashion brands.

\subsubsection{Competitive pressure}

In recent years, the rise of high street brands and light luxury brands has a great impact on luxury brands, especially after luxury brands frequently come out of the "quality gate", consumers' loyalty to luxury brands has decreased. The emergence of fashion brand is a heavy blow to luxury brands. Famous luxury brands have chosen to cooperate with fashion brand or high street brands.

\subsubsection{Interest driven}

The biggest advantage is to quickly open up new markets and invite trendy brands to cooperate, which can build the best bridge between brands and street culture and millennials, so that luxury brands can enter the new consumer market smoothly and establish a good image. Brand alliance can not only quickly shorten the distance between two different consumer markets, expand consumer groups, but also strengthen the awareness of the brand, and pass on the brand culture and connotation value of many years to new consumers, which is one of the better ways to attract new young consumer groups.

\subsection{SWOT analysis of brand alliance}

\subsubsection{Advantages}

The brand alliance of Louis Vuitton and supreme has complementary functions. Louis Vuitton is a well-known traditional luxury brand, and its target customers are more upper middle class; while supreme is the most popular fashion brand of underground street culture, and its main consumers are young consumers aged 20-35. When two completely different consumer groups are integrated into one, it is more conducive to rapidly expand consumer groups to occupy market share.

\subsubsection{Disadvantages}

There is a big difference in the brand image between Louis Vuitton and supreme. Louis Vuitton culture, which started in France and served the nobility, brings more noble and elegant brand image to consumers. However, for more middle-class people, supreme is a kind of young and fashionable culture, and more importantly, it is a kind of street trend brand image with the courage to express oneself and highlight independent personality. When two completely different brand cultures cooperate together, it is easy for consumers to disagree with the product or doubt the brand they once loved, leading to the decrease of loyalty to the original brand.

\subsubsection{Opportunities}

The millennials' demand for product diversity is on the rise. According to the report "global luxury brand market monitoring report spring 2018", the "millennials" mentality is expanding its influence on luxury brands and fashion brands. More and more young and highly educated Chinese are joining the ranks of pursuing street culture. The younger generation of consumers are more interested in "hip hop culture", "self-expression" and "time limited" consumer goods, so they tend to be fashionable and tasteful items as a way to show their unique personality.

\subsubsection{Threats}

The marketing mode of brand alliance has been rampant in the fashion industry. The upsurge of cross-border cooperation brought by fashion brand has been warming up and fermenting in recent years. In particular, the cooperation between luxury brands and fashion brands has attracted the attention of trendsetters and social media. 
Before the brand alliance between Louis Vuitton and supreme, some luxury brands have begun to pay attention to the "sweet cake" of brand alliance. After the joint cooperation is constantly promoted in the consumer market, Louis Vuitton and supreme brand alliance is no longer the unique "secret recipe" of brand marketing.

\subsection{The effect of brand alliance}

According to insider reports, the joint sales of Louis Vuitton and Supreme reached 100 million euro, which successfully increased the popularity of the two brands in the fashion industry and created a commercial miracle. The price of a backpack has risen to 30000 to 60000 yuan. Brand alliance changes the traditional image of luxury, nobility and elegance of Louis Vuitton. Supreme brand injects fresh blood into it, and new patterns open the door of Louis Vuitton to enter the trend. The supreme brand has changed its status in the streets and underground. With the reputation of Louis Vuitton, it has been honored as an elegant lobby, enabling more people in the upper class to support and recognize the brand.

\section{Conclusion}

In recent years, the emergence of fashion brand has a great impact on the luxury brand industry. How to coexist peacefully with fashion brand and survive in the consumer market will be the top issue of luxury brands. In the future, the development trend of fashion industry is still mainly street culture. Under this trend, luxury brands should choose to continue to cooperate with the fashion brand, or create a relevant fashion brand independently, which will be the primary issue for luxury brands in the future. Of course, how to carry out brand alliance more effectively and deeply between luxury brands and fashion brands, how to achieve win-win through brand alliance, and how to solve the conflicts existing in the alliance are also practical problems to be solved.

\section{References}

1. Yu Yan, Zhao Jiguang. Chinese luxury consumption and local brand cultivation [J]. Discussion on modern economy, 2014 (6): 47-51.

2. Chen Jie. Research on the application of online integrated marketing of luxury brands in Chinese market [D]. Master's thesis of Shanghai International Studies University, 2014.

3. Gao Xiaoqian. The influence of luxury goods source country efficiency on consumers' Purchase Intention -- Taking Chinese consumers as an example [J]. Journal of Liaoning University of Technology: Social Science Edition, 2014,16 (3): 265-267.

4. Zhu Yuliang, Yang Yixiong. Case analysis of luxury brand management and marketing: a case study of Hermes [J]. The United States and times · City, 2015 (October 2015): 126-127.
5. Ma Qiang. Thinking on the development of Chinese local luxury brands $[\mathrm{J}]$. Cooperative economy and technology, 2015 (10): 121-122.

6. Zhang Jing. Burberry put down arrogance and become fashionable [J]. Chinese brands, 2011 (6): 82-83.

7. Zhang Tian. Sociological analysis of fashion brand symbol consumption [D]. Master's degree thesis of Southwest University, 2016.

8. Chen Chunqin. Research on brand marketing strategy of fashion brand clothing [J]. Mall modernization, 2017 (3): 57-59 